\title{
Jumlahan Langsung pada Ring
}

\author{
Syafruddin Side ${ }^{1, \text { a) }}$, Muhammad $\mathrm{Abdy}^{1, \text { b) }}$, dan Annisa Uniarti ${ }^{\mathrm{c})}$ \\ ${ }^{1}$ Jurusan Matematika, Fakultas MIPA, Universitas Negeri Makassar \\ a)syafruddin@unm.ac.id \\ ${ }^{b)}$ muh.abdy@unm.ac.id \\ c)annisauniarti@gmail.com
}

\begin{abstract}
Abstrak. Penelitian ini merupakan penelitian kajian pustaka yang bertujuan untuk mengkaji konsep dasar jumlahan langsung eksternal dan jumlahan langsung internal pada ring beserta sifat-sifatnya. Kajian dimulai dari definisi jumlahan langsung eksternal dan jumlahan langsung internal. Adapun literatur utama yang digunakan adalah buku yang ditulis oleh B. Hartley dan T.O. Hawkes (1970). Hasil yang diperoleh menjelaskan dan menguraikan definisi konsep jumlahan langsung eksternal dan jumlahan langsung internal pada ring, teorema-teorema tentang sifat-sifat jumlahan langsung pada ring yang memuat masing-masing sebuah teorema akibat dari representasi sifat jumlahan langsung pada S-Near Ring dan jumlahan langsung pada modul yang berkaitan dengan jumlahan langsung eksternal dan jumlahan langsung internal pada ring.
\end{abstract}

Kata Kunci: Ring, Jumlahan Langsung Eksternal, Jumlahan Langsung Internal.

\begin{abstract}
This research is literature study that aims to examine the basic consept of external direct sum of ring, internal direct sum of ring, and properties of direct sum of ring. The study starts from the definitioan of external direct sum and internal direct sum. The main literature used is a book written by B. Hartley and T.O. Hawkes (1970). The result obtained explain and elaborated on the definitons of external direct sum and internal direct sum of ring, theorems about properties of direct sum of ring that accommodate a theorem resulting from the representation of the properties of direct sum of S-Near Ring and direct sum of modules relating to external rirect sum and internal direct sum of ring.
\end{abstract}

Keywords: Ring, External Direct Sum, Internal Direct Sum.

\section{PENDAHULUAN}

Menurut James (1976), matematika diartikan sebagai ilmu logika mengenai bentuk, susunan, besaran, dan konsep-konsep yang saling berhubungan satu sama lainnya dengan jumlah yang terbagi ke dalam tiga bidang yaitu aljabar, analisis, dan geometri (Side, Sukarna, \& Jusriadi, 2020). Aljabar abstrak atau struktur aljabar merupakan suatu himpunan tak kosong dengan satu atau lebih operasi biner dan memenuhi beberapa aksioma (Sanusi, Abdy, Sidjara, \& Asni, 2020).

Strukur aljabar yang terdiri dari himpunan tak kosong $\mathrm{R}$ dengan satu operasi biner yang memenuhi beberapa aksioma, diantaranya asosiatif, memiliki elemen identitas, memiliki elemen invers dan komutatif dinamakan grup abelian. Sedangkan suatu himpunan tak kosong $\mathrm{R}$ dengan dua operasi biner yaitu operasi penjumlahan $(+)$ dan perkalian $(\times)$ yang memenuhi tiga aksioma diantara yaitu $(R,+)$ berupa grup abelian, operasi kedua $(\times)$ bersifat asosiatif dan operasi kedua $(\times)$ bersifat distributif terhadap operasi pertama $(+)$ disebut ring (Dummit \& Foote, 2004). 
Selain itu, ada pula yang disebut dengan S-near Ring yang tidak jauh berbeda dengan ring, yaitu apabila terdapat himpunan tak kosong $R$ dengan dua operasi biner yaitu operasi penjumlahan $(+)$ dan perkalian $(\times)$ yang memenuhi tiga aksioma diantara yaitu $(R,+)$ berupa grup, operasi kedua $(X)$ bersifat asosiatif dan operasi kedua $(X)$ bersifat distributif kanan terhadap operasi pertama (+) (Patty, 2014). Selanjutnya, struktur aljabar yang mempunyai dua himpunan tak kosong dengan dua operasi biner dan memenuhi syarat-syarat tertentu disebut dengan modul (Wildanianti, 2009).

Selain itu, dalam struktur aljabar, terdapat sebuah operasi yang disebut "jumlahan langsung". Jumlahan langsung dengan jumlahan biasa tidak sama. Pada penjumlahan biasa tidak memperhatikan urutan komponennya, tetapi pada penjumlahan langsung memperhatikan urutaun komponennya (Wildanianti, 2009). Jumlahan langsung terdiri dari jumlahan langsung eksternal dan jumlahan langsung internal. Yunita Wildanianti pada tahun 2009 telah membahas tentang penjumlahan langsung luar dan penjumlahan langsung dalam pada struktur aljabar modul beserta sifat-sifatnya dalam penelitiannya yang berjudul Penjumlahan Langsung pada Modul.

Penelitian ini bertujuan untuk memaparkan definisi dan sifat-sifat dari jumlahan langsung pada ring baik itu jumlahan langsung eksternal maupun jumlahan langsung internal dengan mendetailkan bukti dari teorema yang telah diperoleh dari sumber utama dalam buku Hartley \& Hawkes tahun 1970 dan menunjukkan bahwa beberapa sifat yang berlaku pada struktur aljabar lain juga berlaku pada ring.

\section{KAJIAN TEORI}

Definisi 1 (Tahmir, 2004 \& Judson, 2013)

Misal $G$ himpunan tak kosong, operasi * pada $G$ adalah operasi biner jika untuk setiap $a, b \in G$ maka $a * b \in G$

Definisi 2 (Pinter, 1990 \& Gallian, 2017)

Himpunan tak kosong $G$ dengan sebuah operasi biner * disebut grup jika memenuhi sifat berikut :

(i) Untuk setiap a,b, $c \in G$ berlaku $a *(b * c)=(a * b) * c \in G$ (sifat asosiatif)

(ii) Terdapat $e \in G$ sehingga untuk setiap $a \in G$ berlaku $a * e=e * a=a$ (adanya unsur identitas di $G$ )

Untuk setiap $a \in G$, terdapat $a^{-1} \in G$ sehingga $a * a^{-1}=a^{-1} * a=e$ (adanya unsur invers setiap anggota di $G$ )

Definisi 3 (Clark, 1984 \& Tahmir, 2018)

Misalkan $(G, *)$ dan $\left(G^{\prime}, o\right)$ masing-masing adalah grup. Suatu fungsi $f: G \rightarrow G^{\prime}$ dinamakan suatu homomorpisma jika $f(a * b)=f(a)$ of $(b)$ untuk setiap $a, b \in G$.

Selanjutnya jika $f: G \rightarrow G^{\prime}$ suatu homomorpisma, maka $f$ juga disebut :

a. Monomorpisma jika $f$ injektif

b. Epimorpisma jika $f$ surjektif

c. Isomorpisma jika $f$ bijektif

d. Endomorpisma Jika $G=G^{\prime}$

Automorpisma jika $G=G^{\prime}$ dan $f$ bijektif

Definisi 4 (Dummit dan Foote, 2004 \& Joyce, 2017)

Misalkan $R$ suatu himpunan tak kosong dan pada $R$ di definisikan dua operasi biner yang dinotasikan + dan ', yang selanjutnya disebut operasi penjumlahan dan perkalian. Himpunan $R$ disebut ring terhadap operasi penjumlahan + dan perkalian · jika memenuhhi sifat :

(i) $\quad(R,+)$ merupakan grup komutatif

(ii) Operasi $\cdot$ di $R$ bersifat tertutup, yaitu:

$\left(r_{1} \cdot r_{2}\right) \in R$ 
untuk setiap $r_{1}, r_{2} \in R$

(iii) Operasi $\cdot$ di $R$ bersifat asosiatif, yaitu:

$\left(r_{1} \cdot r_{2}\right) \cdot r_{3}=r_{1} \cdot\left(r_{2} \cdot r_{3}\right)$

untuk setiap $r_{1}, r_{2}, r_{3} \in R$

(iv) Operasi penjumlahan dan perkalian di $R$ bersifat:

a. Distributif kiri:

$r_{1} \cdot\left(r_{2}+r_{3}\right)=\left(r_{1} \cdot r_{2}\right)+\left(r_{1} \cdot r_{3}\right)$, untuk setiap $r_{1}, r_{2}, r_{3} \in R$

b. Distributif kanan:

$\left.\left(r_{1}+r_{2}\right) \cdot r_{3}\right)=\left(r_{1} \cdot r_{3}\right)+\left(r_{2} \cdot r_{3}\right)$, untuk setiap $r_{1}, r_{2}, r_{3} \in R$

Definisi 5 (Suryanti, 2018)

Misalkan $R$ adalah suatu Ring dan I adalah himpunan bagian dari Ring $R$ dengan $I \neq \emptyset$, maka I disebut Ideal dari $R$ jika:

(i) Untuk setiap $s_{1}, s_{2} \in I$, berlaku $s_{1}-s_{2} \in I$

(ii) Untuk setiap $s_{1} \in I$ dan $r \in R$, berlaku $s_{1} r, r s_{1} \in I$

Apabila hanya memenuhi salah satu yaitu untuk setiap $s_{1} \in I$ dan $r \in R$, berlaku $s_{1} r \in I$ maka disebut ideal kanan dan untuk setiap $s_{1} \in I$ dan $r \in R$, berlaku $r s_{1} \in I$ maka disebut ideal kiri.

Teorema 1 (Wahyuni, Wijayanti, Yuwaningsih, \& Hartono, 2016)

Jika $R$ merupakan ring dengan $I_{1}$ dan $I_{2}$ masing-masing merupakan ideal dari $R$, maka

(i) $I_{1} \cap I_{2}$ merupakan ideal di $R$

Bukti

(ii) $I_{1}+I_{2}=\left\{a+b \mid a \in I_{1}\right.$ dan $\left.b \in I_{2}\right\}$ merupakan ideal di $R$

Diketahui $I_{1}$ dan $I_{2}$ masing-masing merupakan ideal dari $R$.

(i) akan dibuktikan $I_{1} \cap I_{2}$ merupakan ideal di $R$.

ambil sebarang $r \in R$ dan $x, y \in I_{1} \cap I_{2}$.

karena $x, y \in I_{1}, x, y \in I_{2}, I_{1}$ dan $I_{2}$ ideal, diperoleh:

1. $x-y \in I_{1}$ dan $x-y \in I_{2}$

2. $r x \in I_{1}$ dan $x r \in I_{1}$

3. $r x \in I_{2}$ dan $x r \in I_{2}$

akibatnya, $x-y \in I_{1} \cap I_{2}, r x \in I_{1} \cap I_{2}$, dan $x r \in I_{1} \cap I_{2}$.

jadi, $I_{1} \cap I_{2}$ merupakan ideal di $R$.

(ii) akan dibuktikan $I_{1}+I_{2}$ merupakan ideal di $R$.

ambil sebarang $r \in R$ dan $x, y \in I_{1}+I_{2}$, tulis $x=a_{1}+a_{2}, y=b_{1}+b_{2}$, untuk suatu $a_{1}, b_{1} \in I_{1}$ dan $a_{2}, b_{2} \in I_{2}$. Karena $I_{1}, I_{2}$ merupakan ideal di $R$ diperoleh $a_{1}-b_{1} \in I_{1}$ dan $a_{2}-b_{2} \in I_{2}, r a_{1} \in I_{1}, a_{1} r \in I_{1}, r a_{2} \in I_{2}, a_{2} r \in I_{2}$ sehingga

1. $x-y=a_{1}+a_{2}-\left(b_{1}+b_{2}\right)$

2. $x r=\left(a_{1}+a_{2}\right) r$

$$
=\left(a_{1}-b_{1}\right)+\left(a_{2}-b_{2}\right) \in I_{1}+I_{2}
$$

3. $r x=r\left(a_{1}+a_{2}\right)$

$$
=a_{1} r+a_{2} r \in I_{1}+I_{2}
$$

$$
=r a_{1}+r a_{2} \in I_{1}+I_{2}
$$

jadi, $I_{1}+I_{2}$ merupakan ideal di $R$

Definisi 6 (Bhattacharya, Jain, \& Nagpaul, 1994 \& Gilbert \& Gilbert, 2015)

misal $A, B$ adalah himpunan. Hasil kali kartesian dari $A$ dan $B$ adalah:

$$
A \times B=\{(x, y) \mid x \in A, b \in B\}
$$

\section{METODE PENELITIAN}

Penelitian yang dilakukan merupakan jenis penelitian dasar atau murni, serta menggunakan metode studi literatur. Yaitu, dengan membaca literatur-literatur yang berhubungan dengan 
jumlahan langsung pada ring. Fokus kajian dalam penelitian ini terletak pada definisi dan teorema dalam jumlahan langsung pada ring.

\section{HASIL PENELITIAN}

Definisi 7 (Hartley dan Hawkes, 1970)

Misalkan $R_{1}, R_{2}, \ldots, R_{n}$ adalah kumpulan ring dan $R$ adalah Hasil kali kartesian pada himpunan $R_{i}$, dan didefinisikan operasi pada $R$ "secara komponen", yaitu:
(i) $\left(r_{1}, r_{2}, \ldots, r_{n}\right)+\left(s_{1}, s_{2}, \ldots, s_{n}\right)=\left(r_{1}+s_{1}, r_{2}+s_{2}, \ldots, r_{n}+s_{n}\right)$
(ii) $-\left(r_{1}, r_{2}, \ldots, r_{n}\right)=\left(-r_{1},-r_{2} \ldots,-r_{n}\right)$
(iii) $\left(r_{1}, r_{2}, \ldots, r_{n}\right)\left(s_{1}, s_{2}, \ldots, s_{n}\right)=\left(r_{1} s_{1}, r_{2} s_{2}, \ldots, r_{n} s_{n}\right)$

Dengan $(0,0, \ldots, 0)$ sebagai elemen nol/identitas. $R$ disebut jumlahan langsung eksternal dari $R_{1}, R_{2}, \ldots, R_{n}$ dan dinotasikan sebagai

$$
R_{1} \oplus R_{2} \oplus \ldots \oplus R_{n}
$$

Definisi 8 (Hartley dan Hawkes, 1970)

Misal $R$ adalah ring, dan $J_{1}, \ldots, J_{n}$ adalah ideal-ideal dari $R$, sedemikian sehingga

(i) $\quad R=\sum_{i=1}^{n} \quad J_{i}$, dan

(ii) $J_{i} \cap \sum_{J \neq i} J_{j}=\{0\}$, untuk $i=1, \ldots, n$.

Maka $\mathrm{R}$ disebut sebagai jumlahan langsung internal dari ideal-ideal $J_{i}$ yang dinotasikan sebagai $R=\oplus J_{i}$

\section{Teorema 2}

Jumlahan langsung eksternal dari ring adalah ring.

\section{Bukti}

Diketahui $R=R_{1} \oplus R_{2} \oplus \ldots \oplus R_{n}$ merupakan jumlahan langsung eksternal dari ring $R_{i}$, dengan $i=1,2, \ldots, n$.

Ambil sebarang $a, b, c \in R$, tulis $a=\left(a_{1}, a_{2}, \ldots, a_{n}\right), b=\left(b_{1}, b_{2}, \ldots, b_{n}\right), c=\left(c_{1}, c_{2}, \ldots, c_{n}\right)$, untuk suatu $a_{1}, b_{1}, c_{1} \in R_{1}, a_{2}, b_{2}, c_{2} \in R_{2}, a_{n}, b_{n}, c_{n} \in R_{n}$, akan ditunjukkan $(R,+$,$) merupakan$ ring.

i. $(R,+)$ grup

1. Tertutup

Untuk setiap $a, b \in R$ berlaku $a+b \in R$.

$a+b=\left(a_{1}, a_{2}, \ldots, a_{n}\right)+\left(b_{1}, b_{2}, \ldots, b_{n}\right)$

$$
=\left(a_{1}+b_{1}, a_{2}+b_{2}, \ldots, a_{n}+b_{n}\right)
$$

dengan $\left(a_{1}+b_{1}\right) \in R_{1},\left(a_{2}+b_{2}\right) \in R_{2}, \ldots,\left(a_{n}+b_{n}\right) \in R_{n}$

jadi $(a+b) \in R$

2. Asosiatif

Untuk setiap $a, b, c \in R$ berlaku $(a+b)+c=a+(b+c)$.

$$
\begin{aligned}
(a+b)+c & =\left(\left(a_{1}, a_{2}, \ldots, a_{n}\right)+\left(b_{1}, b_{2}, \ldots, b_{n}\right)\right)+\left(c_{1}, c_{2}, \ldots, c_{n}\right) \\
& =\left(a_{1}+b_{1}, a_{2}+b_{2}, \ldots, a_{n}+b_{n}\right)+\left(c_{1}, c_{2}, \ldots, c_{n}\right) \\
& =\left(\left(a_{1}+b_{1}\right)+c_{1},\left(a_{2}+b_{2}\right)+c_{2}, \ldots,\left(a_{n}+b_{n}\right)+c_{n}\right) \\
& =\left(a_{1}+\left(b_{1}+c_{1}\right), a_{2}+\left(b_{2}+c_{2}\right), \ldots, a_{n}+\left(b_{n}+c_{n}\right)\right) \\
& =\left(a_{1}, a_{2}, \ldots, a_{n}\right)+\left(\left(b_{1}, b_{2}, \ldots, b_{n}\right)+\left(c_{1}, c_{2}, \ldots, c_{n}\right)\right) \\
& =a+(b+c)
\end{aligned}
$$

3. Terdapat unsur identitas

Untuk setiap $a \in R$, terdapat $e \in R$, sehingga $a+e=e+a=a$. 
Ambil sebarang $a \in R$, akan ditunjukkan terdapat $e \in R$ tulis $e=\left(e_{1}, e_{2}, \ldots, e_{n}\right)$, dengan $e_{1} \in R_{1}, e_{2} \in R_{2}, \ldots, e_{n} \in R_{n}$ sehingga berlaku

$$
a+e=e+a=a
$$

Pilih $0_{R} \in R$, tulis $0_{R}=\left(0_{R_{1}}, 0_{R_{2}}, \ldots, 0_{R_{n}}\right)$, dengan $0_{R_{i}} \in R_{i}, 0_{R_{i}}$ adalah unsur identitas di $R_{i}$.

Perhatikan bahwa:

$$
\begin{aligned}
a+0_{R} & =\left(a_{1}, a_{2}, \ldots, a_{n}\right)+\left(0_{R_{1}}, 0_{R_{2}}, \ldots, 0_{R_{n}}\right) \\
& =\left(a_{1}+0_{R_{1}}, a_{2}+0_{R_{2}}, \ldots, a_{n}+0_{R_{n}}\right) \\
& =\left(a_{1}, a_{2}, \ldots, a_{n}\right) \\
0_{R}+a & =\left(0_{R_{1}}, 0_{R_{2}}, \ldots, 0_{R_{n}}\right)+\left(a_{1}, a_{2}, \ldots, a_{n}\right) \\
& =\left(0_{R_{1}}+a_{1}, 0_{R_{2}}+a_{2}, \ldots, 0_{R_{n}}+a_{n}\right) \\
& =\left(a_{1}, a_{2}, \ldots, a_{n}\right)
\end{aligned}
$$

Jadi $0_{R} \in R$ adalah unsur identitas di $R$.

4. Untuk setiap unsur memiliki invers

Untuk setiap $a \in R$, terdapat $a^{-1} \in R$ sehingga $a+a^{-1}=a^{-1}+a=0_{R}$.

Ambil $a \in R$ sebarang, akan ditunjukkan terdapat $a^{-1} \in R$ sehingga berlaku

Diketahui $0_{R}=\left(0_{R_{1}}, 0_{R_{2}}, \ldots, 0_{R_{n}}\right)$

$$
a+a^{-1}=a^{-1}+a=0_{R}
$$

$$
\begin{aligned}
& a+a^{-1}=0_{R} \\
& \left(a_{1}, a_{2}, \ldots, a_{n}\right)+a^{-1}=\left(0_{R_{1}}, 0_{R_{2}}, \ldots, 0_{R_{n}}\right) \\
& \begin{aligned}
a^{-1} & =\left(0_{R_{1}}, 0_{R_{2}}, \ldots, 0_{R_{n}}\right)-\left(a_{1}, a_{2}, \ldots, a_{n}\right) \\
& =\left(0_{R_{1}}, 0_{R_{2}}, \ldots, 0_{R_{n}}\right)+\left(-a_{1},-a_{2}, \ldots,-a_{n}\right) \\
& =\left(0_{R_{1}}+\left(-a_{1}\right), 0_{R_{2}}+\left(-a_{2}\right), \ldots, 0_{R_{n}}+\left(-a_{n}\right)\right) \\
& =\left(-a_{1},-a_{2}, \ldots,-a_{n}\right) \in R
\end{aligned}
\end{aligned}
$$

Sehingga $a^{-1}=\left(-a_{1},-a_{2}, \ldots,-a_{n}\right)$ adalah unsur invers untuk setiap $a \in R$.

5. Untuk setiap $a, b \in R$ berlaku $a+b=b+a$

$$
\begin{aligned}
(a+b) & =\left(a_{1}, a_{2}, \ldots, a_{n}\right)+\left(b_{1}, b_{2}, \ldots, b_{n}\right) \\
& =\left(a_{1}+b_{1}, a_{2}+b_{2}, \ldots, a_{n}+b_{n}\right) \\
& =\left(b_{1}+a_{1}, b_{2}+a_{2}, \ldots, b_{n}+a_{n}\right)\left[\text { karena } a_{i}, b_{i} \in R_{i}, i=1,2, \ldots, n\right] \\
& =b+a
\end{aligned}
$$

ii. $(R, \cdot)$ semigrup

1. Tertutup

Untuk setiap $a, b \in R$ berlaku $a \cdot b \in R$.

$$
\begin{aligned}
& a \cdot b=\left(a_{1}, a_{2}, \ldots, a_{n}\right) \cdot\left(b_{1}, b_{2}, \ldots, b_{n}\right) \\
& \quad=\left(a_{1} b_{1}, a_{2} b_{2}, \ldots, a_{n} b_{n}\right) \\
& \text { dengan }\left(a_{1} b_{1}\right) \in R_{1},\left(a_{2} b_{2}\right) \in R_{2}, \ldots,\left(a_{n} b_{n}\right) \in R_{n} \\
& \text { jadi }(a \cdot b) \in R
\end{aligned}
$$

2. Asosiatif

Untuk setiap $a, b, c \in R$ berlaku $(a \cdot b) \cdot c=a \cdot(b \cdot c)$.

$$
\begin{aligned}
(a \cdot b) \cdot c & =\left(\left(a_{1}, a_{2}, \ldots, a_{n}\right) \cdot\left(b_{1}, b_{2}, \ldots, b_{n}\right)\right) \cdot\left(c_{1}, c_{2}, \ldots, c_{n}\right) \\
& =\left(a_{1} \cdot b_{1}, a_{2} \cdot b_{2}, \ldots, a_{n} \cdot b_{n}\right) \cdot\left(c_{1}, c_{2}, \ldots, c_{n}\right) \\
& =\left(\left(a_{1} \cdot b_{1}\right) \cdot c_{1},\left(a_{2} \cdot b_{2}\right) \cdot c_{2}, \ldots,\left(a_{n} \cdot b_{n}\right) \cdot c_{n}\right) \\
& =\left(a_{1} \cdot\left(b_{1} \cdot c_{1}\right), a_{2} \cdot\left(b_{2} \cdot c_{2}\right), \ldots, a_{n} \cdot\left(b_{n} \cdot c_{n}\right)\right) \\
& =\left(a_{1}, a_{2}, \ldots, a_{n}\right) \cdot\left(\left(b_{1}, b_{2}, \ldots, b_{n}\right) \cdot\left(c_{1}, c_{2}, \ldots, c_{n}\right)\right) \\
& =a \cdot(b \cdot c)
\end{aligned}
$$

3. $(R,+, \cdot)$ distributif kanan dan kiri

Untuk setiap $a, b, c \in R$, berlaku:

1. $(a+b) . c=a \cdot c+b \cdot c$

2. $a \cdot(b+c)=a \cdot b+a \cdot c$ 
1. Distributif kanan

$$
\begin{aligned}
(a+b) . c= & \left(\left(a_{1}, a_{2}, \ldots, a_{n}\right)+\left(b_{1}, b_{2}, \ldots, b_{n}\right)\right) \cdot\left(c_{1}, c_{2}, \ldots, c_{n}\right) \\
= & \left(a_{1}+b_{1}, a_{2}+b_{2}, \ldots, a_{n}+b_{n}\right) \cdot\left(c_{1}, c_{2}, \ldots, c_{n}\right) \\
= & \left(\left(a_{1}+b_{1}\right) \cdot c_{1},\left(a_{2}+b_{2}\right) \cdot c_{2}, \ldots,\left(a_{n}+b_{n}\right) \cdot c_{n}\right) \\
= & \left(\left(a_{1} \cdot c_{1}\right)+\left(b_{1} \cdot c_{1}\right),\left(a_{2} \cdot c_{2}\right)+\left(b_{2} \cdot c_{2}\right), \ldots,\left(a_{n} \cdot c_{n}\right)+\quad\left(b_{n} \cdot c_{n}\right)\right) \\
& =\left(a_{1} \cdot c_{1}, a_{2} \cdot c_{2}, \ldots, a_{n} \cdot c_{n}+b_{1} \cdot c_{1}, b_{2} \cdot c_{2}, \ldots, b_{n} \cdot c_{n}\right) \\
= & \left(a_{1}, a_{2}, \ldots, a_{n}\right) \cdot\left(c_{1}, c_{2}, \ldots, c_{n}\right)+\left(b_{1}, b_{2}, \ldots, b_{n}\right) \cdot \\
& \left(c_{1}, c_{2}, \ldots, c_{n}\right) \\
= & a \cdot c+b \cdot c
\end{aligned}
$$

2. Distributif kiri

$$
\begin{aligned}
a \cdot(b+c)= & \left(a_{1}, a_{2}, \ldots, a_{n}\right) \cdot\left(\left(b_{1}, b_{2}, \ldots, b_{n}\right)+\left(c_{1}, c_{2}, \ldots, c_{n}\right)\right) \\
= & \left(a_{1}, a_{2}, \ldots, a_{n}\right) \cdot\left(b_{1}+c_{1}, b_{2}+c_{2}, \ldots, b_{n}+c_{n}\right) \\
= & \left(a_{1} \cdot\left(\left(b_{1}+c_{1}\right), a_{2} \cdot\left(b_{2}+c_{2}\right), \ldots, a_{n} \cdot\left(b_{n}+c_{n}\right)\right)\right. \\
= & \left(\left(a_{1} \cdot b_{1}\right)+\left(a_{1} \cdot c_{1}\right),\left(a_{2} \cdot b_{2}\right)+\left(a_{2} \cdot c_{2}\right), \ldots,\left(a_{n} \cdot b_{n}\right)\right. \\
& \left.+\left(a_{n} \cdot c_{n}\right)\right) \\
= & \left(a_{1} \cdot b_{1}, a_{2} \cdot b_{2}, \ldots, a_{n} \cdot b_{n}+a_{1} \cdot c_{1}, a_{2} \cdot c_{2}, \ldots, a_{n} \cdot c_{n}\right) \\
= & \left(a_{1}, a_{2}, \ldots, a_{n}\right) \cdot\left(b_{1}, b_{2}, \ldots, b_{n}\right)+\left(a_{1}, a_{2}, \ldots, a_{n}\right) \cdot \\
& \left(c_{1}, c_{2}, \ldots, c_{n}\right) \\
= & a \cdot b+a \cdot c
\end{aligned}
$$

\section{Teorema 3}

Jika $R=\oplus P_{i}$, dengan $P_{i}$ ideal dari $R, i=1,2, \ldots, n$ dengan:

$$
\begin{aligned}
& Q_{1}=P_{1}+P_{2}+\cdots+P_{k_{1}} \\
& Q_{2}=P_{k_{1}+1}+P_{k_{1}+2}+\cdots+P_{k_{1}+k_{2}} \\
& Q_{3}=P_{k_{1}+k_{2}+1}+P_{k_{1}+k_{2}+2}+\cdots+P_{k_{1}+k_{2}+k_{3}} \\
& \cdot \\
& \cdot \\
& Q_{r}=P_{k_{1}+k_{2}+\ldots+k_{r-1}+1}+P_{k_{1}+k_{2}+\cdots+k_{r-1}+2}+\cdots+P_{n} \\
& \text { maka } R=\bigoplus Q_{j}, j=1,2, \ldots, r .
\end{aligned}
$$

\section{Bukti}

Diketahui $R=\oplus P_{i}$, dengan $P_{i}$ ideal dari $R, i=1,2, \ldots, n$ dan

$Q_{1}=P_{1}+P_{2}+\cdots+P_{k_{1}}$

$Q_{2}=P_{k_{1}+1}+P_{k_{1}+2}+\cdots+P_{k_{1}+k_{2}}$

$Q_{3}=P_{k_{1}+k_{2}+1}+P_{k_{1}+k_{2}+2}+\cdots+P_{k_{1}+k_{2}+k_{3}}$

$Q_{r}=P_{k_{1}+k_{2}+\cdots+k_{r-1}+1}+P_{k_{1}+k_{2}+\ldots+k_{r-1}+2}+\cdots+P_{n}$

akan dibuktikan $R=\oplus Q_{j}, j=1,2, \ldots, r$.

karena $R=\oplus P_{i}$ maka berlaku:

$$
\begin{aligned}
R= & P_{1}+P_{2}+\cdots+P_{n} \\
& =P_{1}+P_{2}+\cdots+P_{k_{1}}+P_{k_{1}+1}+P_{k_{1}+2}+\cdots+P_{k_{1}+k_{2}}+P_{k_{1}+k_{2}+1}+ \\
& P_{k_{1}+k_{2}+k_{3}}+\cdots+P_{k_{1}+k_{2}+\cdots+k_{r-1}+1}+P_{k_{1}+k_{2}+\cdots+k_{r-1}+2}+\cdots+P_{n} \\
= & Q_{1}+Q_{2}+Q_{3}+\ldots+Q_{r} \quad[\text { tetap ideal }] \\
= & \oplus Q_{j}
\end{aligned}
$$

Teorema 4 (Hartley dan Hawkes, 1970) 
Jika $R$ adalah jumlahan langsung internal dari ideal-ideal $J_{1}, J_{2}, \ldots, J_{n}$, maka untuk setiap $r \in R$ dapat ditulis secara tunggal bentuk

dengan $r_{i} \in J_{i}$

$$
r=r_{1}+r_{2}+\cdots+r_{n}
$$

\section{Bukti}

Misalkan $r_{1}+r_{2}+\cdots+r_{n}=r_{1}{ }^{\prime}+r_{2}{ }^{\prime}+\cdots+r_{n}{ }^{\prime}$, dengan $r_{i}, r_{i}{ }^{\prime} \in J_{i}$. akan ditunjukkan $r_{i}=r_{i}{ }^{\prime}$. perhatikan bahwa

$$
\begin{aligned}
& r_{1}+r_{2}+\cdots+r_{n}=r_{1}{ }^{\prime}+r_{2}{ }^{\prime}+\cdots+r_{n}{ }^{\prime} \\
& \Leftrightarrow\left(r_{1}+r_{2}+\cdots+r_{n}\right)-\left(r_{1}{ }^{\prime}+r_{2}{ }^{\prime}+\cdots+r_{n}{ }^{\prime}\right)=0 \\
& \Leftrightarrow\left(r_{1}-r_{1}{ }^{\prime}\right)+\left(r_{2}-r_{2}{ }^{\prime}\right)+\cdots+\left(r_{n}-r_{n}{ }^{\prime}\right)=0 \\
& \Leftrightarrow\left(r_{1}-r_{1}{ }^{\prime}\right)+\left(r_{2}-r_{2}{ }^{\prime}\right)+\cdots+\left(r_{i-1}-r_{i-1}\right)+\left(r_{i}-r_{i}{ }^{\prime}\right)+\left(r_{i+1}-r_{i+1}{ }^{\prime}\right)+\cdots+\left(r_{n}-\right. \\
& \left.r_{n}{ }^{\prime}\right)=0 \\
& \Leftrightarrow r_{i}-r_{i}^{\prime}=-\left(r_{1}-r_{1}{ }^{\prime}\right)-\left(r_{2}-r_{2}{ }^{\prime}\right)-\cdots-\left(r_{i-1}-r_{i-1}{ }^{\prime}\right)-\left(r_{i}-r_{i}{ }^{\prime}\right)-\left(r_{i+1}-r_{i+1}{ }^{\prime}\right)- \\
& \cdots-\left(r_{n}-r_{n}{ }^{\prime}\right) \\
& \Leftrightarrow r_{i}-r_{i}^{\prime}=\left(r_{1}{ }^{\prime}-r_{1}\right)+\left(r_{2}{ }^{\prime}-r_{2}\right)+\cdots+\left(r_{i-1}{ }^{\prime}-r_{i-1}\right)+\left(r_{i}{ }^{\prime}-r_{i}\right)+\left(r_{i+1}{ }^{\prime}-r_{i+1}\right)+ \\
& \cdots+\left(r_{n}{ }^{\prime}-r_{n}\right)
\end{aligned}
$$

karena $r_{i}, r_{i}^{\prime} \in J_{i}$, maka $r_{i}-r_{i}^{\prime} \in J_{i}$

selanjutnya karena $r_{1}^{\prime}-r_{1} \in J_{1}, r_{2}^{\prime}-r_{2} \in J_{2}, \ldots, r_{i-1}^{\prime}-r_{i-1} \in J_{i-1}, r_{r+1}^{\prime}-r_{i+1} \in J_{i+1}, \ldots$, $r_{n}^{\prime}-r_{n} \in J_{n}$, maka $\sum_{j \neq i} \quad\left(r_{j}^{\prime}-r_{j}\right)=r_{i}-r_{i}^{\prime} \in \sum_{j \neq i} \quad J_{j}$

perhatikan bahwa $R$ merupakan jumlahan langsung internal, sehingga

$$
J_{i} \cap \sum_{j \neq i} J_{j}=\{0\}
$$

karena $r_{i}-r_{i}^{\prime} \in J_{i}$ dan $r_{i}-r_{i}^{\prime} \in \sum_{j \neq i} \quad J_{j}$, akibatnya $r_{i}-r_{i}^{\prime} \in J_{i} \cap \sum_{j \neq i} \quad J_{j}=\{0\}$ sehingga diperoleh $r_{i}-r_{i}^{\prime}=0$

dengan bentuk lain $r_{i}=r_{i}^{\prime}$.

Jadi, untuk setiap $r \in R$ dapat ditulis secara tunggal bentuk $r=r_{1}+r_{2}+\cdots+r_{n}$ dengan $r_{i} \in J_{i}$.

\section{PEMBAHASAN}

Penelitian yang dilakukan oleh Wildanianti (2009) yang berjudul penjumahan langsung pada modul telah menunjukkan tentang konsep dari penjumlahan langsung luar dan dalam pada modul, yaitu penjumlahan langsung luar adalah perkalian langsung dari kumpulan modul dan jumlahan langsung dalam adalah penjumlahan langsung dari kumpulan submodul yang memenuhi syarat tertentu. Sementara dalam penelitian ini didapatkan konsep dari jumlahan langsung eksternal dan jumlahan langsung internal yaitu jumlahan langsung eksternal adalah hasil kali kartesian dari kumpulan ring $R_{1}, R_{2}, \ldots, R_{n}$ yang dinotasikan dengan $R=R_{1} \oplus R_{2} \oplus \ldots \oplus R_{n}$ yang telah di bahas dalam Definisi 7, jumlahan langsung internal adalah kumpulan dari ideal-ideal di $R$ yang memenuhi $R=\sum_{i=1}^{n} \quad J_{i}$, dan $J_{i} \cap \sum_{J \neq i} J_{j}=\{0\}$, untuk $i=1, \ldots, n$, dimana $J_{i}$ adalah idealideal di $R$ yang telah di bahas dalam Definisi 8 .

Penelitian yang dilakukan oleh Patty (2014) yang berjudul hasil kali langsung $S$-near-ring dan $S$ near-ring bebas menunjukkan bahwa sebuah jumlahan langsung dari $S$-near-ring adalah $S$-nearring, hal ini mendasari terbentuknya Teorema 2 dengan tujuan untuk membuktikan bahwa sifat tersebut juga berlaku pada ring. Selanjutnya, penelitian Wildanianti (2009) juga membahas sebuah teorema yang menunjukan bahwa jumlahan langsung internal dari submodul-submodul katakan $M$ yang apabila jumlah dari tiap submodul merupakan jumlah dari submodul-submodul 
lain maka $M$ juga merupakan jumlahan langsung internal dari submodul-submodul lain tersebut. Hal ini mendasari terbentuknya Teorema 3. Selain itu, dalam penelitian ini juga telah dibahas Teorema 4 yang menunjukkan bahwa bentuk $r=r_{1}+r_{2}+\cdots+r_{n}$, dengan $r_{i} \in J_{i}$ hanya dapat ditulis secara tunggal untuk setiap $r \in R$, di mana $R$ adalah jumlahan langsung internal dari idealideal nya yaitu $J_{i}, i=1,2, \ldots, n$.

\section{KESIMPULAN}

Berdasarkan hasil penelitian yang dipaparkan sebelumnya, telah diperoleh dengan jelas konsep dari jumlahan langsung eksternal dan jumlahan langsung internal pada ring yang tidak jauh berbeda dengan penjumlahan langsung luar dan penjumlahan langsung dalam pada modul. Selain itu, beberapa sifat jumlahan langsung pada struktur aljabar selain ring juga berlaku pada ring.

\section{DAFTAR PUSTAKA}

Bhattacharya, P.B., Jain, S.K., Nagpaul, S.R. (1994). Basic Abstract Algebra. Inggris: Cambridge University Press

Clark, A. (1984). Elements of Modern Algebra. New york: Dover Publisher, Inc.

Dummit, D.S., \& Foote, R.M. (2004). Abstract Algebra. United States of America: Laurie Rosatone

Gallian, J.A. (2017). Contemporary Abstract Algebra. United States of America: Cengage Learning

Gilbert, L., \& Gilbert, J. (2005). Elements of Modern Algebra. United States of America: Cengage Learning

Hartley, B., \& Hawkes, T.O. (1970). Rings, Modules, and Linear Algebra. Inggris: Cambridge University Press

Joyce, D. (2017). Introduction to Modern Algebra. United States of America: Clark University

Judson, T.W. (2013). Abstract Algebra. United States of America: Stephan F. Austin State University

Patty, H.W.M, (2014). Hasil Kali Langsung S-Near-Ring dan S-Near-Ring Bebas. Jurnal Barekang, 8(2). 1-7.

Pinter, C.C. (1990). A Book of Abstract Algebra. New York: Dover Publisher, Inc.

Sanusi, W., Abdy, M., Sidjara,S., \& Asni, A.A. (2020). Suatu Kajian Tentang B-Aljabar. Journal of Mathematics, Computasion, and Statistics, 3(2). 118-125.

Side,S., Sukarna., \& Jusriadi. (2020). Analisis Matematika Pada Pembuatan Rumah Panggung Toraja. Journal of Mathematics, Computasion, and Statistics, 3(1). 1-10.

Suryanti, S. (2018). Teori Ring. Gresik: UGM Press

Tahmir, S. (2004). Teori Grup. Makassar: Andira Publisher

Tahmir, S. (2018). Struktur Aljabar. Makassar: Badan Penerbit Universitas Negeri Makassar

Wahyuni, S., Wijayanti, I.E., Yuwaningsih, D.A., Hartono, A.D. (2016). Teori Ring dan Modul. Yogyakarta: Gadjah Mada University Press.

Wildanianti, Y. (2009). Penjumlahan Langsung pada Modul. (Skripsi). Universitas Islam Negeri Maulana Malik Ibrahim, Malang. 